\title{
Effects of a transtheoretical model - based intervention and motivational interviewing on the management of depression in hospitalized patients with coronary heart disease: a randomized controlled trial
}

\author{
Xiaoyun $\mathrm{Li}^{1,2+}$, Silan Yang ${ }^{1+}$, Yishu Wang ${ }^{3}$, Bingxiang Yang ${ }^{4}$ and Jingping Zhang ${ }^{1 *}$ (D)
}

\begin{abstract}
Background: Depression is a major risk factor for the morbidity and mortality of cardiovascular disease. A transtheoretical model-based intervention and motivational interviewing have been used to change health risk behaviors and have demonstrated positive effects. To our knowledge, no studies of patients with coronary heart disease (CHD) have used a transtheoretical model-based intervention and motivational interviewing as an intervention to provide dynamic education. Therefore, this study aimed to determine the effects of the transtheoretical model-based intervention and motivational interviewing on the management of depression in hospitalized patients with CHD.
\end{abstract}

Method: A randomized controlled trial was designed. A total of 110 participants were randomly divided into an intervention group $(n=55)$ and a control group $(n=55)$. The Hamilton Rating Scale for Depression and the Depression Prevention \& Management Survey items (stages of change, perceived benefits, perceived barriers, process of change and self-efficacy) were used to collect data at all time points. Analysis of covariance, chi-square test and repeated measures analysis of variance were used to analyze the data.

Results: After the intervention, there were more positive changes in stages of change, higher scores for the cognitive and behavioral levels, the perceived benefits, and self-efficacy, and lower perceived barriers and depression in the intervention group than in the control group. Finally, there were statistically significant differences in the depression scores at different time points in the intervention group $(F=17.814, p=0.000<0.01)$.

Conclusions: The study showed that a transtheoretical model-based intervention and motivational interviewing exert positive effects on the management of depression in hospitalized patients with CHD.

Trial registration: Clinicaltrials.gov, NCT03953924 (Date assigned: 16/5/2019). Retrospectively registered.

Keywords: Transtheoretical model, Motivational interviewing, Depression, Coronary heart disease

\footnotetext{
* Correspondence: jpzhang1965@csu.edu.cn

†Xiaoyun Li and Silan Yang contributed equally to this study.

Xiaoyun Li and Silan Yang have shared the first authorship equally.

'Xiangya Nursing School of Central South University, 172 Tong Zi Po Road,

Changsha 410000, Hunan, China

Full list of author information is available at the end of the article
}

C C The Author(s). 2020 Open Access This article is licensed under a Creative Commons Attribution 4.0 International License, which permits use, sharing, adaptation, distribution and reproduction in any medium or format, as long as you give appropriate credit to the original author(s) and the source, provide a link to the Creative Commons licence, and indicate if changes were made. The images or other third party material in this article are included in the article's Creative Commons licence, unless indicated otherwise in a credit line to the material. If material is not included in the article's Creative Commons licence and your intended use is not permitted by statutory regulation or exceeds the permitted use, you will need to obtain permission directly from the copyright holder. To view a copy of this licence, visit http://creativecommons.org/licenses/by/4.0/. The Creative Commons Public Domain Dedication waiver (http://creativecommons.org/publicdomain/zero/1.0/) applies to the data made available in this article, unless otherwise stated in a credit line to the data. 


\section{Background}

In the twentieth century, coronary heart disease (CHD) was the most common cause of death in the United States [1]. The Chinese health service survey showed that approximately 100,000 320,000 people were suffering from CHD in mainland China in 2008 [2]. Studies have indicated that the global cardiovascular mortality rate is expected to increase by $50 \%$, and the number of deaths from cardiovascular diseases in Asian countries will double by 2020 [3]. The high mortality and morbidity of CHD will aggravate the psychological burden of patients, such as inducing depression. A study reported that the prevalence of depression in patients with CHD ranged from 8.2 to $35.7 \%$ in men and from 10.3 to $62.5 \%$ in women [4]. The incidence of depression in the Chinese population was reported to be in the range of $4 \%$ $6 \%$ and as high as $14 \% \sim 17 \%$ in patients with CHD [5].

Many studies have shown that the occurrence, development and prognosis of, as well as recovery from CHD are closely related to depression [6, 7]. Depression not only affects the patients' state of an illness but also reduces their quality of life and their compliance to medication treatment regimens and lifestyle changes [8,9]. In addition, depression is a major risk factor for the morbidity and mortality of cardiovascular disease [10, 11]. A study of 30,239 patients, with an average follow-up time of 5.95 years, found that patients with $\mathrm{CHD}$ who were depressed had a higher risk of death than those without depression [6]. Studies have also shown that depressive symptoms were associated with a higher probability of mental stress-induced myocardial ischemia in patients with CHD [12, 13]. Therefore, there is an urgent need to screen for and treat depression in patients with CHD.

The American Heart Association recommended screening for depression in patients with CHD and subsequently be given appropriate treatment [14]. At present, the treatment for depression in patients with CHD includes antidepressant administration [15]. However, these medications have side effects. Other methods of treatment are psychological interventions, which include psychological counseling, knowledge education, relaxation therapy [16], cognitive behavioral therapy and so on [17]. Depression has been alleviated after psychological therapies, but a systematic review in Cochrane suggested considerable uncertainty surrounding these effects [18]. In addition, the content of these psychological interventions and knowledge education were not based on dynamically changing knowledge or other needs, such as self-cognition or self-efficacy. These studies cannot provide an analysis of staged results in the process of psycho-behavioral change. From what was discussed above, it is imperative that a new and dynamic intervention is used to alleviate depression in patients with CHD.
The transtheoretical model (TTM) is a purposeful behavioral change model. It is a systematic study of people's behavior change based on a variety of theories. The intervention based on TTM was designed to guide intervention methods to change dangerous behaviors [19]. TTM includes four parts: stages of change (SOC), process of change (POC), decisional balance (DB), and self-efficacy (SE). DB includes perceived benefits and perceived barriers. SOC is divided into five stages: precontemplation, contemplation, preparation, action, and maintenance [20]. Effective outcomes with TTM have also been observed with health risk behaviors such as smoking [21], unhealthy alcohol use [22] and weight control [23].

In addition, another method used to involve individuals in health behavior change is motivational interviewing (MI). MI takes an approach to interpersonal communication with patients as the center, which helps patients discover and overcome their ambivalence, thereby triggering behavioral changes [24]. It is an instructional way of communicating that invites people to think about their own situation and find their own solution [24]. A systematic review showed that MI might have favorable effects on changing patients' depression and found that the effect of a single use of MI was better than that of cognitivebehavioral therapy [25]. Moreover, a study confirmed that educational and promotional interventions based on TTM and MI may change the behavior of psychiatric patients and positively influence their nutrition habits [26]. In summary, TTM-based interventions and MI have been used to change health behaviors and have demonstrated positive effects. To our knowledge, no studies using a TTM-based intervention and $\mathrm{MI}$ as an intervention to provide dynamic education have been conducted in patients with CHD. Therefore, we decided to determine the effects of a TTMbased intervention and MI on the management of depression in hospitalized patients with CHD and to provide patient-centered, accessible assistance to strengthen the patients' ability to manage depression. Using an existing model as a foundation, we developed a mediating framework to depict the intervention pathway (Fig. 1).

\section{Methods \\ Aim}

The aim of this study was to determine the effects of a TTM-based intervention and MI on the management of depression in hospitalized patients with CHD. The study's hypotheses were as follows: (1) The patients in the intervention group, compared with those in the control group, would show a positive shift in the stages of change and on scores for measures of cognition, behavior, perceived benefits, self-efficacy, and perceived barriers after the intervention; (2) The patients in the intervention group would 


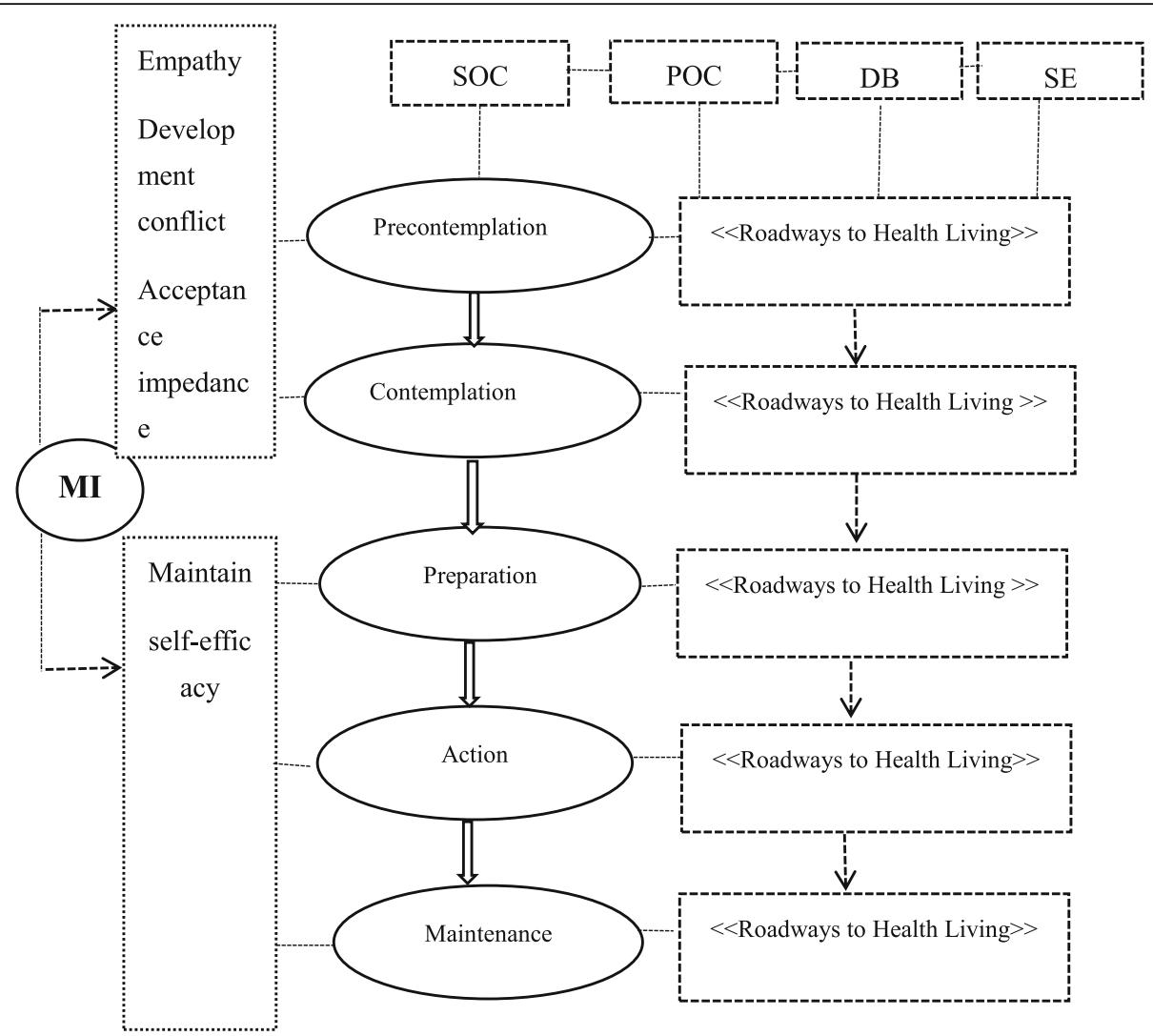

Fig. 1 Conceptual framework

achieve significant improvement in their depression compared with those in the control group.

\section{Trial design}

The study was a single-blind, parallel, randomized, controlled trial and officially approved by the Institutional Review Board (IRB) of the Second Xiangya Hospital, Central South University (Changsha, Hunan Province, China) (NO. 2015S038). The patients were from three Central South University-affiliated general tertiary hospitals in Changsha, Hunan province, China. They were randomly divided into two groups by using a block randomization list with a block size of 4 at 1:1 by an investigator who did not participate in the study. A research assistant put the generated random numbers into opaque, consecutively numbered envelopes, sealed the envelopes, and then handed them to the enrolling researchers. When an eligible patient was recruited into the study, the enrolling researcher gave the patient a number and opened the sealed envelope with the same number. The enrolling researchers were blinded to the design of this study.

\section{Sample size}

Considering the main purpose of the study, a $5 \%$ level of significance (two-tailed test) and a power of 0.90 were adopted: the sample size was calculated on the basis of the formula for sample size required to compare the mean of two samples [27]: $n_{1}=n_{2}=2\left[\frac{\left(u_{\alpha}+u_{\beta}\right)}{\delta / \sigma}\right]^{2}+\frac{1}{4} u_{\alpha}^{2}$; with reference to Yang's study in patients with depression [28], effect size $=\delta / \sigma=\left(\mu_{1}-\mu_{2}\right) / \sigma=(8.32-6.02) /$ $3.34=0.689$. In this study, $\mu_{\alpha / 2}=1.960, \beta=0.1, \mu_{0.01}=$ 1.282, the sample size in each group: $\mathrm{n}_{1}=\mathrm{n}_{2}=2 \times$ $((1.960+1.282) / 0.689)^{2}+1 / 4 \times 1.960^{2} \approx 46$; considering a $20 \%$ attrition rate, 55 patients in each group would be adequate to meet parametric test assumptions.

\section{Recruitment and eligibility}

The sample was 110 hospitalized patients with CHD in the Medicine-Cardiovascular Departments of three hospitals in Changsha. The eligibility criteria were as follows: (1) diagnosed with CHD (typical clinical angina manifestations, electrocardiographic changes, and coronary angiography) confirmed by the World Health Organization / International Cardiology guidelines from October 1997, with cardiac function graded from $I$ to $W$; (2) had a level of education that was primary school or above; (3) volunteered to participate in the study; (4) had a clear consciousness and were able to express their wishes. 
The exclusion criteria were as follows: (1) patients who had cerebrovascular accident, malignant oncology, malignant hypertension (systolic pressure $>180$ and/or diastolic pressure $>100 \mathrm{mmHg}$ ); (2) patients who had psychiatric history or serious cognitive or consciousness obstacles; (3) patients who had participated in other similar research studies; (4) patients who could not be contacted by mobile phone or home phone.

\section{Consent procedures}

Participants were informed of the purpose, significance, and methods of the research, the time that was required to fill out the questionnaire, and the possible risks and benefits of the study so that the patients could fully understand the content and how the study would progress.

\section{Interventions}

\section{Contact the hospital}

The leader of research team contacted the hospital and obtained the consent of the relevant departments and cardiovascular internal medicine inpatient ward heads of the hospital to screen the potential research participants before the beginning of the study.

\section{TTM-based intervention and MI}

The patients in the intervention group received usual care (only in relation to their physical health) and the TTM-based intervention and MI, while those in the control group were given usual care. Trained nurses provided the patient interventions. The trained nurses consisted of one research leader and experienced nurses, all of whom had qualifications as national psychological counselors, who were familiar with and responsible for the CHD patients. The research leader informed the patients of the schedule for each session using the educational manual "Roadways to Health Living-guidelines for the management of depression", which was developed by one psychologist, one experienced nurse, and related researchers. The experienced nurse was trained by the researcher about the intervention content and the process.

The MI was implemented 2 times, 20 min each time, and the trained nurses interviewed each patient face-to-face at bedside. The change stages of the patients' behavior changes were identified by motivational interviewing. According to the change stage, the trained nurses adopted the face-to-face approach and incorporated corresponding measures to explain the contents of the manual named "Roadways to Health Living". At the end of the baseline assessment, the patient was given the manual and guided reading. The TTM-based intervention was given 3 times in the form of a small course, $20 \mathrm{~min}$ each time, and each course was based on the manual.
The TTM-based intervention included 3 sessions: (1) In the first session, for patients who were in precontemplation or contemplation stage, we focused on the related knowledge of depression and CHD, in order to make patients understand the importance of management of depression to physical and mental health and the benefits of management of depression; (2) In the second session, for patients who were in reparation or action stage, we provided specific strategies and methods to help them manage depression and enhance their skills, We negotiated and made a action plan for change with patients; (3) In the third session, for patients who were in maintenance stage, we provide examples and experiences of successful improvement of depression, and affirm the efforts and achievements of patients to make them keep the will of action. Besides, we explored the situation that may hinder the action and provided the relevant coping strategies. Tables 1 and 2 show detailed descriptions of the intervention.

Sessions were held in a meeting room at 2 time points: 2-7 days after baseline assessment and 2 days before discharge in the two groups. The initial session included MI and the TTM-based intervention. The second session included MI and 2 TTM-based interventions. The intervention flow diagram is shown in Fig. 2.

All variables were collected at 2 time points: when the patient was admitted ( $\mathrm{T}$, obtain the baseline information) and 2 days before discharge (T0; i.e., the information obtained after the intervention) by another research assistant who was blinded to the study design and allocation of the participants used questionnaire. The data collection time between two times was approximately 2 weeks.

Table 1 Description of the interventions received by the patients in each group

\begin{tabular}{ll}
\hline Control group & Intervention group \\
\hline Usual care: received & Usual care \\
support only in relation & MI $^{\mathrm{a}}$ : Two sessions of 20-min \\
to their physical health. & face-to-face contact. \\
& (i) Risks, relevance, rewards, \\
roadblocks, repetition; \\
$T \mathrm{TM}^{\mathrm{b}}$ : Three sessions of 30-min \\
face-to-face contact. \\
(i) An introduction to depression \\
and coronary heart disease; \\
(ii) Strategies for management \\
of depression; \\
(iii) Experience in improving \\
depression, situations that may \\
interfere with action, and ways \\
to deal with it. \\
A manual about the management \\
of depression covering all the \\
above mentioned content. \\
(i) TTM-based intervention+Ml.
\end{tabular}

${ }^{\mathrm{a}} \mathrm{Ml}$ motivational interviewing, ${ }^{\mathrm{b}} T T M$ transtheoretical model 
Table 2 Goals and strategies for the management of depression in each stage

\begin{tabular}{|c|c|c|c|}
\hline Stage & Goal & Strategies & Techniques and processes of change \\
\hline $\begin{array}{l}\text { Precontemplation } \\
\text { Contemplation }\end{array}$ & $\begin{array}{l}\text { Finding and establishing the } \\
\text { intrinsic motivation of behavior } \\
\text { change through interviewing. } \\
\text { Improve depression. }\end{array}$ & $\begin{array}{l}\text { Provide knowledge about } \\
\text { depression and CHD and the } \\
\text { risks of depression (physical and } \\
\text { psychosocial health). } \\
\text { Encourage thinking about the benefits } \\
\text { of improvements in depression. }\end{array}$ & $\begin{array}{l}\text { Listening and guidance. } \\
\text { Consciousness awakening, } \\
\text { emotional arousal, self-reevaluation, } \\
\text { environmental reevaluation and } \\
\text { social liberation. }\end{array}$ \\
\hline $\begin{array}{l}\text { Preparation } \\
\text { Action }\end{array}$ & $\begin{array}{l}\text { Increase motivation and Confidence. } \\
\text { Negotiate and make action plan for } \\
\text { change. } \\
\text { Take action to alleviate depression. }\end{array}$ & $\begin{array}{l}\text { Provide specific strategies to prevent } \\
\text { and manage depression. } \\
\text { Help patients enhance their skills and } \\
\text { develop action plans. }\end{array}$ & $\begin{array}{l}\text { Timely confirmation. } \\
\text { Awakening consciousness, helping } \\
\text { relationships, self-emancipation, } \\
\text { enhancing management and } \\
\text { situational substitution. }\end{array}$ \\
\hline Maintenance & $\begin{array}{l}\text { Keep following up in hospital. } \\
\text { Enhance patients' self-confidence } \\
\text { in managing depression. }\end{array}$ & $\begin{array}{l}\text { Provide examples and experiences of } \\
\text { successful improvement of depression, } \\
\text { and affirm the efforts and achievements } \\
\text { of patients. } \\
\text { Explore situations that may hinder action. } \\
\text { Provide appropriate coping strategies. }\end{array}$ & $\begin{array}{l}\text { Helping relationships, self-emancipation, } \\
\text { enhanced management, situational } \\
\text { substitution, and stimulus control. }\end{array}$ \\
\hline
\end{tabular}

\section{Measures}

Primary outcome measures

Hamilton rating scale for depression (HRSD) Depression was measured by the HRSD. The scale was compiled in 1960 by Hamilton [29] and includes 24 items. A few items (4th, 5th, 6th, 12th, 14th, 16th, 17th, 18th, and 21st items) were evaluated with a 0-2-point scoring method, and the remaining items were evaluated with a 0-4-point scoring method. The higher the total scores were, the worse the depression. According to Davis JM [30], a score of 8 to 19 indicated no depressive symptoms, more than 20 indicated mild or moderate depression, and more than 35 indicated severe depression. In this study, Cronbach's alpha was 0.819 .

Depression Prevention \& Management Survey (DPMS) items SOC, DB, POC and SE were measured by DPMS. The original English edition of the questionnaire was compiled by the American Pro-Change Behavior

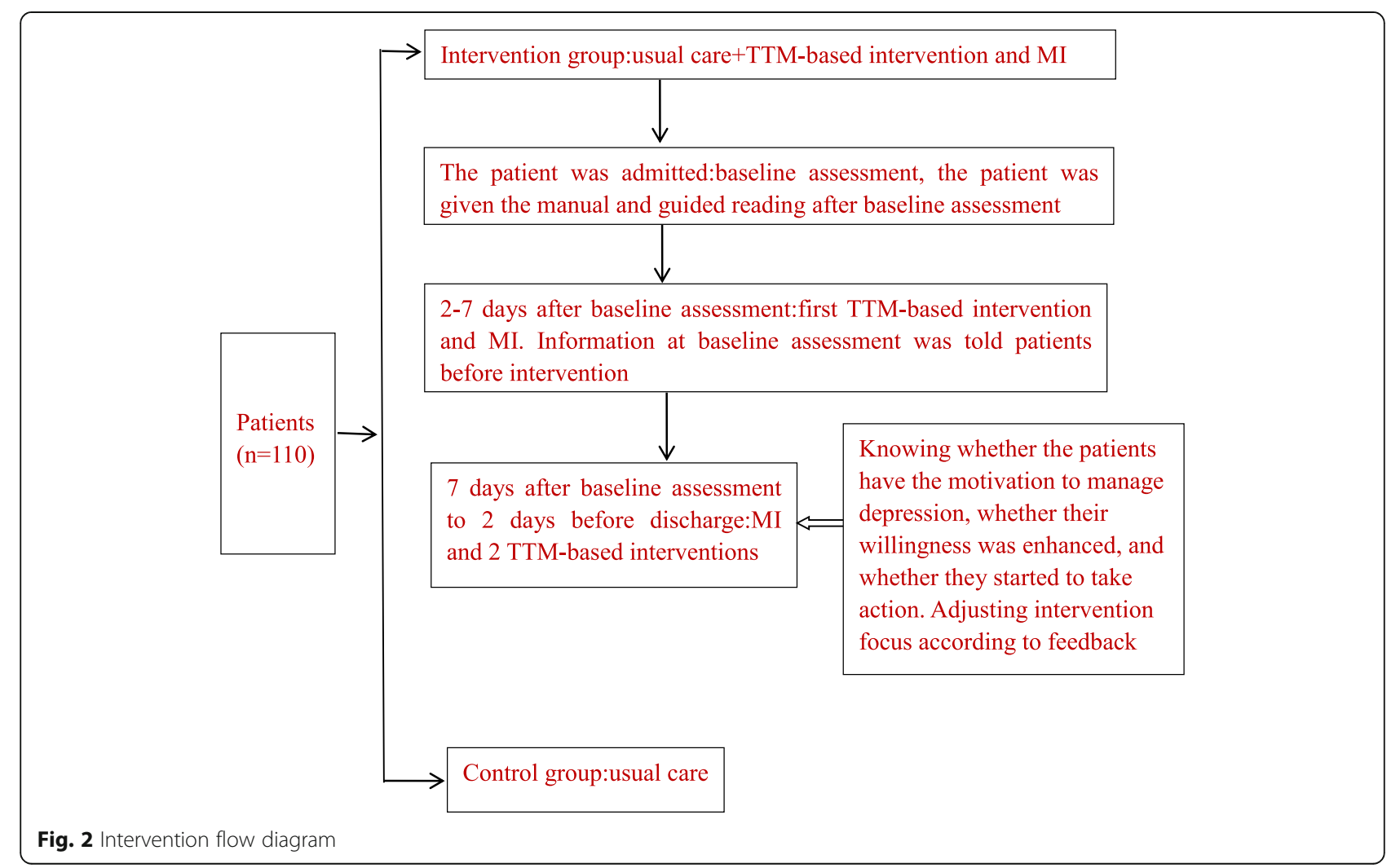


Systems, Inc. Research Center. The form used in the present study was developed with authorization, preliminary work involving a pilot test, related literature review, modification based on a previous TTM intervention [28, 31], and consultation with six experts, including a psychologist, two experienced researchers in depression, a professor of cardiovascular internal medicine, and two bilingual nursing scholars with academic background. The index of content validity (CVI) was 0.988 . The management of depression questionnaire mainly included four subscales: SOC, POC, DB, and SE subscale.

SOC subscale The SOC subscale was used for measuring the stage of an individual's depression management behavior and consisted of one item: "do you take effective ways to prevent and manage depression (enjoyable activities, keep trying to fight stress, and seek professional help if necessary and so on) in your daily life?". There were five statements: precontemplation ('no, and I'm not planing to do that in the next 6 months'), contemplation ('no, but I plan to start in the next 6 months'), preparation ('no, but I plan to start in the next 30 days'), action ('yes, I have been doing that for more than 1 day and less than 6 months'), and maintenance ('yes, I have been doing that for more than 6 months'). The patients were asked to select one suitable statement. The scale has good reliability $(0.790)$ and retest reliability.

POC subscale The POC subscale was used to evaluate individuals' experiences or activities that can influence individuals to take effective measures to manage depression. It had 30 items and included cognitive and behavioral levels. Each item was scored from 1 (never) to 5 (always). The higher the score for a particular dimension was, the higher the frequency of use of that process. The Cronbach's alpha of cognitive processes and behavioral processes was 0.786 and 0.817 , respectively.

DB subscale The DB subscale was used to assess the importance an individual placed on effectively managing depression and determine the importance of taking action for an individual. It comprised 12 items and two dimensions that included perceived benefits and perceived barriers. Each item was scored from 1 (not important) to 5 (extremely important). The Cronbach's alpha values of the perceived benefits and perceived barriers were 0.690 and 0.700 , respectively.

SE subscale The SE subscale consisted of 6 items. Each item was scored from 1 (no confidence at all) to 5 (full of confidence), and the scores reflected the degree of confidence in effectively managing depression. Higher scores reflected higher confidence. The Cronbach's alpha of the subscale was 0.735 .

\section{Secondary outcome measures}

Social demographic data recording form (SDDRF) The SDDRF was used to collect patient demographic information such as age, sex, education, disease diagnosis and treatment-related data, such as cardiac function.

\section{Statistical method}

All statistical analyses were completed using SPSS 18.0. Descriptive statistics were used to report participant demographic data. Chi-square tests was used to compare the differences in means of the outcome variables between the two groups at the 2 time points. An analysis of covariance was used to examine the effects of the intervention on the various indexes of depression management. Repeated measures analysis of variance (ANOVA) were used to evaluate the effects of the intervention and the timeintervention interaction on depression management.

\section{Results \\ Participant characteristics}

Finally, a total of 103 valid patients were obtained: the control group $(n=55)$ and the intervention group $(n=48)$. The participant flow diagram is shown in Fig. 3. In terms of demographic and clinical characteristics of the samples, the mean age of the participants was $63.3 \pm 7.89$ years. There were no significant differences in demographic and clinical characteristics between the two groups at baseline $(p>0.05)$ (Table 3). No serious events associated with the intervention occurred throughout the study.

Effect of the intervention on the SOC for CHD depression Inter-group comparisons between the two groups at the two time points ( $T$ and $T_{0}$ )

A chi-square test was adopted to compare the differences between the two groups at $\mathrm{T}$ and $\mathrm{T}_{0}$. Table 4 shows that the number of precontemplation patients in the intervention group decreased, while the number of patients in the contemplation, preparation and action stages increased, and these differences between the two groups were significant at $\mathrm{T}_{0}(p=0.000<0.01)$.

\section{Intra-group comparison at the two time points for stage changes in the intervention group}

A chi-square test was adopted to compare the differences in the number of patients in each stage at the two time points $\left(T\right.$ and $T_{0}$ ) in the intervention group. There was a significant difference in the number of patients in each stage at the two time points $(F=$ $14.898, p=0.002<0.01)$. 


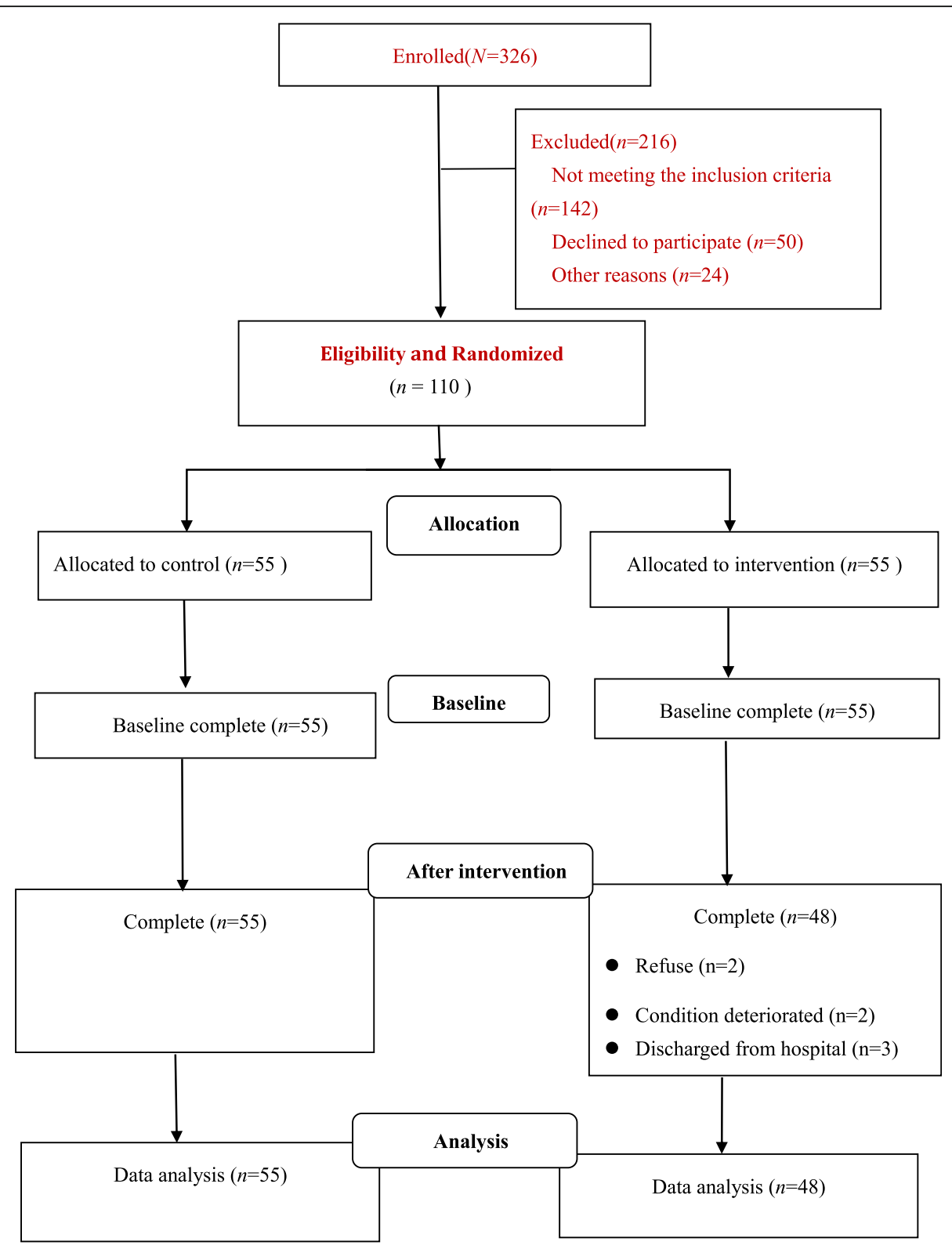

Fig. 3 Patient flow diagram

Effect of the intervention on the various indexes of

\section{depression management}

Comparison of the $D B, P O C$, and SE scores for depression in the CHD patients between two groups after intervention

An analysis of covariance was adopted to examine the effects of the intervention on the DB, POC, SE and depression scores. The regression coefficient test results of perceived benefits, perceived barriers, cognitive level, behavioral level, self-efficacy and depression $(F=2.237$, $P=0.138 ; F=0.014, P=0.905 ; F=0.892, P=0.347 ; F=$ $0.254, P=0.615 ; F=0.106, P=0.745 ; F=0.122, p=0.728)$ meet the basic assumption. Table 5 shows that the scores of the indexes between the two groups were all statistically significantly different after the intervention when excluding the influence of each index score before intervention $(p<0.01)$.

ANOVA showed that the main effect of the intervention on each dimension of $\mathrm{DB}$, various dimensions of POC and SE showed statistical significance at the two time points except depression $(p<0.05)$. The scores of perceived benefits, perceived barriers, cognitive level, behavioral level, and SE varied with time and showed statistical significance in the main effect of time $(p<0.05)$. There was an interaction between the time factor $(T$ and $T_{0}$ ) and intervention for each index with the exception of perceived barriers $(p<0.05)$ (Table 6). 
Table 3 Demographic and clinical characteristics of the patients

\begin{tabular}{|c|c|c|c|c|}
\hline & \multirow{2}{*}{$\begin{array}{l}\text { Intervention } \\
\text { Group }(\boldsymbol{n}= \\
\text { 48) } \\
\mathrm{n}(\%)\end{array}$} & \multirow{2}{*}{$\begin{array}{l}\text { Control } \\
\text { Group } \\
(\boldsymbol{n}=55) \\
\mathrm{n}(\%)\end{array}$} & \multicolumn{2}{|c|}{ Chi-squared test } \\
\hline & & & $x^{2}$ & $P$ \\
\hline \multicolumn{5}{|l|}{ Sex } \\
\hline Men & $30(62.5)$ & $36(65.5)$ & 0.100 & 0.755 \\
\hline Women & $18(37.5)$ & $19(34.5)$ & & \\
\hline \multicolumn{5}{|l|}{ Age } \\
\hline$\leq 60$ years & 19 (39.6) & $17(30.9)$ & 6.950 & 0.073 \\
\hline $61-65$ years & $6(12.5)$ & $18(32.7)$ & & \\
\hline $66-70$ years & $14(10.7)$ & $9(16.4)$ & & \\
\hline$\geq 71$ years & $9(18.8)$ & $11(20.0)$ & & \\
\hline \multicolumn{5}{|l|}{ Marital status } \\
\hline Married & $45(93.7)$ & $48(87.3)$ & 1.230 & 0.268 \\
\hline Widowed or others & $3(6.3)$ & $7(12.7)$ & & \\
\hline \multicolumn{5}{|l|}{ Education } \\
\hline Primary school & $13(27.1)$ & $14(25.5)$ & 0.400 & 0.940 \\
\hline Junior middle school & $13(27.1)$ & $18(32.7)$ & & \\
\hline High school or Secondary specialized school & $15(31.3)$ & $16(29.1)$ & & \\
\hline College and above & $7(14.6)$ & $7(12.7)$ & & \\
\hline \multicolumn{5}{|l|}{ Occupation } \\
\hline Workers & $24(50.0)$ & $31(56.4)$ & 1.240 & 0.743 \\
\hline Farmers & $14(29.2)$ & $12(21.8)$ & & \\
\hline Cadres & $8(16.7)$ & $8(14.5)$ & & \\
\hline Others & $2(4.2)$ & $4(7.3)$ & & \\
\hline \multicolumn{5}{|l|}{ Type of medical payment } \\
\hline Public or medical insurance & $34(70.8)$ & $41(74.5)$ & 0.180 & 0.673 \\
\hline Rural cooperative medical care & $14(29.2)$ & $14(25.5)$ & & \\
\hline \multicolumn{5}{|l|}{ Cardiac function } \\
\hline 1 & $9(18.8)$ & $9(16.4)$ & 0.950 & 0.623 \\
\hline$\|$ & 19 (39.6) & $27(49.1)$ & & \\
\hline III & $20(41.7)$ & $19(34.5)$ & & \\
\hline \multicolumn{5}{|l|}{ Percutaneous coronary intervention } \\
\hline Yes & $24(50.0)$ & $26(47.3)$ & 0.080 & 0.782 \\
\hline No & $24(50.0)$ & $29(52.7)$ & & \\
\hline \multicolumn{5}{|l|}{ Number of complications } \\
\hline One & $18(37.5)$ & $19(34.5)$ & 0.100 & 0.952 \\
\hline Two & 19 (39.6) & $23(41.8)$ & & \\
\hline Three & $11(22.9)$ & $13(23.6)$ & & \\
\hline \multicolumn{5}{|l|}{ Duration of disease (years) } \\
\hline$\leq 3$ & $18(37.5)$ & $14(25.5)$ & 1.740 & 0.419 \\
\hline $3-5$ & $17(35.4)$ & $23(41.8)$ & & \\
\hline$\geq 5$ & $13(27.1)$ & $18(32.7)$ & & \\
\hline
\end{tabular}

Levels of depression throughout the study

The depression scores decreased more in the intervention group than in the control group. In addition, there were statistically significant differences in the depression scores at different time points in the intervention group $(F=17.814, p=0.000<0.01)$. 
Table 4 Comparisons of the number of patients in the stages of change between the two groups at two time points

\begin{tabular}{|c|c|c|c|c|}
\hline \multirow[t]{2}{*}{ Stages of change } & \multirow{2}{*}{$\begin{array}{l}\text { Intervention } \\
\text { group }(\boldsymbol{n}= \\
\text { 48) } \\
\mathrm{n}(\%)\end{array}$} & \multirow{2}{*}{$\begin{array}{l}\text { Control } \\
\text { group } \\
(\boldsymbol{n}=55) \\
\mathrm{n}(\%)\end{array}$} & \multicolumn{2}{|c|}{ Chi-squared test } \\
\hline & & & $x^{2}$ & $P$ \\
\hline \multicolumn{5}{|l|}{$T$} \\
\hline Precontemplation & $30(62.5)$ & $41(74.5)$ & 2.551 & 0.466 \\
\hline Contemplation & 16 (33.3) & $13(23.6)$ & & \\
\hline Preparation & $1(2.1)$ & $1(1.82)$ & & \\
\hline Action & $1(2.1)$ & $0(0.0)$ & & \\
\hline Maintenance & $0(0.0)$ & $0(0.0)$ & & \\
\hline \multicolumn{5}{|l|}{$T_{o}$} \\
\hline Precontemplation & $15(31.2)$ & $38(69.1)$ & 22.198 & $0.000^{* *}$ \\
\hline Contemplation & 19 (39.6) & $16(29.1)$ & & \\
\hline Preparation & $12(25.0)$ & $0(0.0)$ & & \\
\hline Action & $2(4.2)$ & $1(1.8)$ & & \\
\hline Maintenance & $0(0.0)$ & $0(0.0)$ & & \\
\hline
\end{tabular}

\section{Discussion}

The results showed after the intervention there were significantly more positive changes in the SOC, POC, DB (more perceived benefits, fewer perceived barriers), SE (higher) and depression (lower) measures in the intervention group than in the control group. These positive effects were consistent with previous studies about depression [31] and stress management [20, 32]. These findings were in line with the results of similar studies, suggesting this model intervention was effective [33-35].

\section{Effect of the intervention on the SOC for depression in patients with CHD}

The majority of patients were in the precontemplation stage (intervention group $=62.5 \% \quad(30 / 48)$; control group $=74.5 \%(41 / 55))$ at baseline. The number of patients in the intervention group in the precontemplation, contemplation, action stages increased after the intervention, and in the control group, there were almost no improvements. This positive effect was consistent with previous studies in depression [31] and stress management [32], which found that the change stages moved forward after the intervention.

The TTM points out that whether an individual's behavior change can be transferred from the previous stage to the next stage depends on the change process at each stage, including at the cognitive and behavioral levels [36]. Patients in the precontemplation stage may initially be uninformed or insufficiently aware of the consequences of their behaviors, and some people do not view the behavior as a problem [37]. At the beginning of the study, we found through MI that most of the patients with CHD did not understand what was depression, especially patients with a relatively low educational level who may have never heard of depression. Half of the patients did not know of the harmful consequences of depression on CHD. In addition, under the influence of Chinese Confucianism, some people were unwilling to admit that they had depression. Therefore, in view of these characteristics, the TTM-based intervention focused on providing relevant knowledge about depression and CHD, enabling patients to understand the importance and benefits of prevention and management of depression on physical and mental health and trying to adopt effective methods. For patients in the stages of preparation, action, and maintenance, MI focused on strengthening patient confidence in behavior change to promote patient progress though the stages of change.

\section{Effect of the intervention on the DB of depression in patients with CHD}

The results showed that the patients in the intervention group demonstrated more perceived benefits and fewer perceived barriers than the control group after the

Table 5 Comparison of two groups of patients on decisional balance, the process of change, self-efficacy and depression after intervention

\begin{tabular}{|c|c|c|c|c|c|c|}
\hline \multirow[t]{2}{*}{ Items } & \multicolumn{4}{|l|}{ Analysis of covariance } & \multicolumn{2}{|c|}{ Adjusted mean (95\%Cl) } \\
\hline & $\begin{array}{l}\text { Intervention }(\boldsymbol{n}=48) \\
(\bar{X} \pm s)\end{array}$ & $\begin{array}{l}\text { Control }(\boldsymbol{n}=55) \\
(\bar{X} \pm s)\end{array}$ & $F(d f)$ & $P$ & Intervention $(\boldsymbol{n}=48)$ & Control $(\boldsymbol{n}=55)$ \\
\hline \multicolumn{7}{|l|}{ Decisional balance } \\
\hline Perceived benefits & $10.19 \pm 2.10$ & $8.73 \pm 1.13$ & $33.641(1.000)$ & $0.000^{* *}$ & $10.20(9.83,10.57)$ & $8.71(8.37,9.06)$ \\
\hline Perceived barriers & $6.58 \pm 1.30$ & $7.93 \pm 1.12$ & $18.995(1.000)$ & $0.000^{* *}$ & $6.75(6.42,7.09)$ & $7.78(7.47,8.09)$ \\
\hline \multicolumn{7}{|l|}{ Process of change } \\
\hline Cognitive level & $33.94 \pm 5.57$ & $29.35 \pm 3.09$ & $67.769(1.000)$ & $0.000^{* *}$ & $34.52(33.53,35.51)$ & $28.84(27.91,29.76)$ \\
\hline Behavioral level & $34.44 \pm 5.01$ & $32.78 \pm 2.87$ & $42.466(1.000)$ & $0.000^{* *}$ & $34.47(35.37,37.56)$ & $31.01(30.00,32.01)$ \\
\hline Self-efficacy & $12.06 \pm 2.40$ & $10.47 \pm 1.57$ & $15.443(1.000)$ & $0.000^{* *}$ & $12.00(12.46,12.54)$ & $10.53(10.02,11.03)$ \\
\hline Depression & $18.46 \pm 3.36$ & $20.85 \pm 2.28$ & $25.515(1.000)$ & $0.000^{* *}$ & $18.30(17.53,19.07)$ & $20.99(20.28,21.71)$ \\
\hline
\end{tabular}

${ }^{* *} p<0.01$ 
Table 6 Analysis of the effect of time and intervention on perceived benefits, the process of change and self-efficacy

\begin{tabular}{|c|c|c|c|c|c|c|}
\hline \multirow[t]{2}{*}{ Items } & \multicolumn{2}{|c|}{ Intervention main effect } & \multicolumn{2}{|l|}{ Time main effect } & \multicolumn{2}{|l|}{ Interaction } \\
\hline & $F(d f)$ & $p$ & $F(d f)$ & $p$ & $F(d f)$ & $p$ \\
\hline \multicolumn{7}{|l|}{ Decisional balance } \\
\hline Perceived benefits & $5.956(1.000)$ & $0.016^{*}$ & $42.819(1.000)$ & $0.000^{* *}$ & $28.924(1.000)$ & $0.000^{* *}$ \\
\hline Perceived barriers & $29.134(1.000)$ & $0.000^{* *}$ & $5.702(1.000)$ & $0.019^{*}$ & $1.327(1.000)$ & 0.252 \\
\hline \multicolumn{7}{|l|}{ Process of change } \\
\hline Cognitive level & $4.659(1.000)$ & $0.033^{*}$ & $132.663(1.000)$ & $0.000^{* *}$ & $74.881(1.000)$ & $0.000^{* *}$ \\
\hline Behavioral level & $12.517(1.000)$ & $0.001^{* *}$ & $164.765(1.000)$ & $0.000^{* *}$ & $129.878(1.000)$ & $0.000^{* *}$ \\
\hline Self-efficacy & $10.535(1.000)$ & $0.002^{* *}$ & $106.989(1.000)$ & $0.000^{* *}$ & $10.923(1.000)$ & $0.001^{* *}$ \\
\hline Dpression & $0.170(1.000)$ & 0.681 & $74.730(1.000)$ & $0.000^{* *}$ & $14.199(1.000)$ & $0.000^{* *}$ \\
\hline
\end{tabular}

intervention. This finding is in line with the results of similar studies, as this model intervention was effective [38].

DB reflects the individual's relative weighing of the pros and cons of changing [39]. There are two dimensions: the perceived benefits (the benefits and reasons for the behavioral change) and the perceived barriers (the negative aspects and obstacles to the behavioral change) [19]. During the intervention, the patients often underestimated the benefits of preventing and managing depression. Therefore, in the current study, the researchers incorporated each patient's characteristics into the intervention to help patients recognize the direct and potential benefits of depression prevention and management, emphasize the most relevant benefits for the patients, and make the patients identify possible barriers, thereby providing the available solutions. In the intervention manual, we provided detailed lists of the benefits of taking effective methods to prevent and manage depression, such as 'I will feel more healthy', 'my sleep will be improved', 'I will be more attractive', 'the pain will be eased', etc. In addition, the manual for patients with possible barriers to the process of behavior change also provides the corresponding countermeasures, as a way to "counter" the barrier; for example, a patient may think "depression is my family's inheritance so I can do nothing for it", and the counter would suggest "if I'm truly a depressed person at high risk, I should work harder to prevent and manage it".

\section{Effect of the intervention on the POC of depression in patients with CHD}

This study showed that the increases in the cognitive level and behavioral level in the intervention group was significantly higher than those in the control group. The results were similar to the results of the study by Fallon et al. in which people reported greater use of the cognitive and behavioral level of change [40]. The early stages of SOC (precontemplation, contemplation, and preparation) mainly reflect changes at the cognitive level, which increases the willingness of patients to engage in the behavioral change, the later stages (preparation, action, and maintenance) indicate changes at the behavioral level and reflect the aim to undertake observable and maintainable efforts [41], and the transition from the cognitive level to behavioral level indicates the progress across the SOC [42]. In this study, we designed the corresponding intervention strategies according to the influencing factors at all levels of the change process and adopted different psychological intervention measures for patients at different stages according to the relationship between the SOC and POC. The intervention aimed at the most critical problem of behavior change for the patients in each stage, and the most direct approaches were adopted to achieve the maximum intervention effect. Thus, the goal of transforming patients into the next stage of behavior change in the shortest time can be achieved.

\section{Effect of the intervention on SE of depression in patients with CHD}

$\mathrm{SE}$ is defined as how well one can execute courses of action required to deal with prospective situations [43]. SE can strongly affect behavioral change [44]. The people with high self-efficacy will make enough effort, which will lead to successful results if executed well, while those with low self-efficacy may stop working hard and fail early [45]. This study demonstrated that SE in the intervention group increased more than that in the control group after the intervention. These results were consistent with those of Zhu et al. [35], who found that the ESMI group demonstrated a higher exercise SE than the control group. Behavior change is an important outcome variable. The change in cognitive and behavioral changes in patients is an effective evaluation index of this study. This study was aimed at individual behavior change so that each patient can easily see his or her progress, then he or she can establish enough self-confidence and persist in the behavioral change to alleviate depression. 
This study showed that the depression scores in the CHD patients in the control group decreased to a certain extent. The depression of the patients may be related to the disease itself [28], and if the disease was controlled after treatment, the depression level consequently decreased. However, the depression in the intervention group decreased more than that in the control group due to the additional psychological intervention.

To summarize, these findings suggest that a TTMbased intervention and face-to-face MI were effective in the management of depression in hospitalized patients with CHD. However, the study had three limitations: the first limitation was no long-term follow-up. Therefore, future studies should pay more attention to long-term follow-up to fully verify the progress of all the theoretical stages of TTM and MI. The second limitation was no blinding of the patients, i.e., it was a single-blind trial. Finally, we did not consider the significance of subclinical symptoms of depression. Considering the subclinical symptoms, studies examining depression should be using more than one measurement tool in the future.

\section{Conclusion}

This study confirms that a psychological TTM-based intervention and MI could produce positive effects on depression in hospitalized patients with CHD. The intervention could raise the cognitive level, behavioral level, perceived benefits, and SE, and reduce perceived barriers. This finding will provide guidance for future patient depression and behavior management.

\section{Abbreviations \\ CHD: Coronary heart disease; TTM: Transtheoretical model; MI: Motivational interviewing; SOC: Stages of change; POC: Process of change; DB: Decisional balance; SE: Self-efficacy; SDDRF: Social Demographic Data Recording Form; HRSD: Hamilton Rating Scale for Depression; T: Patients on admission (at baseline); $T_{0}$ : Patients 2 days before discharge and after the intervention}

\section{Acknowledgments}

We would like to express our heartfelt thanks to all patients and hospitals in this study. We would like to acknowledge and thank professor James $\mathrm{O}$. Prochaska and professor James M. Prochaska, Ph.D. who gave the study support.

\section{Authors' contributions}

$J Z$ designed the study, interpreted the results, and provided consultation in the study design and the intervention development process. $\mathrm{XL}$ designed the study, collected the data, analyzed the data and interpreted the results. SY analyzed and interpreted the data, wrote the manuscript, prepared the manuscript and revised the manuscript. YW and BY conducted statistical analysis and provided consultation in the study design and the intervention development process. All authors reviewed the final manuscript prior to submission. All authors read and approved the final manuscript.

\section{Funding}

No funding was obtained for this study.

\section{Ethics approval and consent to participate}

This trial was approved by official approval from the Institutional Review Board (IRB) of the Second Xiangya Hospital, Central South University (Changsha, Hunan Province, China) (NO. 2015S038). The participant consent was written

\section{Consent for publication}

Not applicable.

\section{Competing interests}

The authors declare that they have no competing interests.

\section{Author details}

${ }^{1}$ Xiangya Nursing School of Central South University, 172 Tong Zi Po Road, Changsha 410000, Hunan, China. '2Department of Nephrology, The Second Xiangya Hospital of Central South University, Changsha, Hunan, China. ${ }^{3}$ The Second Xiangya Hospital of Central South University, Changsha, Hunan, China. ${ }^{4}$ Health Sciences of Wuhan University, Wuhan, Hubei, China.

Received: 17 May 2019 Accepted: 23 March 2020

Published online: 30 March 2020

\section{References}

1. Dalen JE, Alpert JS, Goldberg RJ, Weinstein RS. The epidemic of the 20(th) century: coronary heart disease. Am J Med. 2014;127(9):807-12.

2. Ministry of health P. China Health Statistics Yearbook. Beijing: China Union Medical University Publisher; 2012.

3. Hu Dayi MC. Cardiology practice 2011: new developments and clinical cases. Beijing: People's Medical Publishing House; 2011.

4. Pajak A, Jankowski P, Kotseva K, Heidrich J, de Smedt D, De Bacquer D. Depression, anxiety, and risk factor control in patients after hospitalization for coronary heart disease: the EUROASPIRE III study. Eur J Prev Cardiol. 2013;20(2):331-40

5. Zhu Jifang LY, Chaorong C, Li L. Investigation of anxiety and depression status and influencing factors in patients with coronary heart disease. Laser Magazine. 2014;35(9):127-9.

6. Alcantara C, Muntner P, Edmondson D, Safford MM, Redmond N, Colantonio LD, Davidson KW. Perfect storm: concurrent stress and depressive symptoms increase risk of myocardial infarction or death. Circ Cardiovasc Qual Outcomes. 2015;8(2):146-54.

7. Carney RMFK. Depression and coronary heart disease. Nat Rev Cardiol. 2017; 143(3):145-55.

8. Summers KM, Martin KE, Watson K. Impact and clinical management of depression in patients with coronary artery disease. Pharmacotherapy. 2010; 30(3):304-22..

9. Belialov Fl. Depression, anxiety, and stress in patients with coronary heart disease. Ter Arkh. 2017:89(8):104-9.

10. Pizzi C, Santarella L, Bugiardini R. Epidemiology and the physiopathological link between depression and cardiovascular disease. ljc Metab Endocr. 2014; 5(c):52-5.

11. Pizzi C, Costa GM, Santarella L, Flacco ME, Capasso L, Bert F, Manzoli L. Depression symptoms and the progression of carotid intima-media thickness: a 5-year follow-up study. Atherosclerosis. 2014;233(2):530-6.

12. Boyle SH, Samad Z, Becker RC, Williams R, Kuhn C, Ortel TL, Kuchibhatla M, Prybol K, Rogers J, O'Connor C, et al. Depressive symptoms and mental stress-induced myocardial ischemia in patients with coronary heart disease. Psychosom Med. 2013;75(9):822-31.

13. Wei J, Pimple P, Shah AJ, Rooks C, Bremner JD, Nye JA, lbeanu I, Murrah N, Shallenberger $L$, Raggi $P$, et al. Depressive symptoms are associated with mental stress-induced myocardial ischemia after acute myocardial infarction. PLoS One. 2014;9(7):e102986.

14. Lichtman JH, Bigger JT Jr, Blumenthal JA, Frasure-Smith N, Kaufmann PG, Lesperance F, Mark DB, Sheps DS, Taylor CB, Froelicher ES. Depression and coronary heart disease: recommendations for screening, referral, and treatment: a science advisory from the American heart association prevention committee of the council on cardiovascular nursing, council on clinical cardiology, council on epidemiology and prevention, and interdisciplinary council on quality of care and outcomes research: endorsed by the American psychiatric association. Circulation. 2008;118(7): 1768-75. 
15. Ostuzzi G, Turrini G, Gastaldon C, Papola D, Rayner L, Caruso R, Grassi L, Hotopf M, Barbui C. Efficacy and acceptability of antidepressants in patients with ischemic heart disease. Int Clin Psychopharmacol. 2019;34(2):65-75.

16. Orth-Gomer K, Schneiderman N, Wang HX, Walldin C, Blom M, Jernberg T. Stress reduction prolongs life in women with coronary disease: the Stockholm Women's intervention trial for coronary heart disease (SWITCHD). Circ Cardiovasc Qual Outcomes. 2009;2(1):25-32.

17. Aghaei MSE, Mahdavi A, Faraji J, Roshandel Z. Effectiveness of behavioralcognitive group therapy on depression, anxiety, and stress of patients with coronary heart disease. J Med Life. 2015;8(Spec Iss 4):252-7.

18. Richards SH, Anderson L, Jenkinson CE, Whalley B, Rees K, Davies P, Bennett $P$, Liu Z, West R, Thompson DR, et al. Psychological interventions for coronary heart disease. Cochrane Database Syst Rev. 2017;4:CD002902.

19. Prochaska JODC. Toward a more integrative model of change. Psychother Theor Res Pract. 1982;19(3):276-88.

20. Prochaska JO, Butterworth S, Redding CA, Burden V, Perrin N, Leo M, Flaherty-Robb M, Prochaska JM. Initial efficacy of MI, TTM tailoring and HRI's with multiple behaviors for employee health promotion. Prev Med. 2008; 46(3):226-31.

21. James O, Prochaska WFV, Fava JL, Rossi JS, Tsoh JY. Evaluating a populationbased recruitment approach and a stage-based expert system intervention for smoking cessation. Addict Behav. 2001;26(4):583-602.

22. Baumann S, Gaertner B, Schnuerer I, Bischof G, John U, Freyer-Adam J. How well do TTM measures work among a sample of individuals with unhealthy alcohol use that is characterized by low readiness to change? Psychol Addict Behav. 2013;27(3):573-83.

23. Johnson SS, Paiva AL, Cummins CO, Johnson JL, Dyment SJ, Wright JA, Prochaska JO, Prochaska JM, Sherman K. Transtheoretical model-based multiple behavior intervention for weight management: effectiveness on a population basis. Prev Med. 2008;46(3):238-46.

24. Rollnick SMW. What is motivational interviewing? Behav Cogn Psychother. 1995:23(4):325-34.

25. Lee WW, Choi KC, Yum RW, Yu DS, Chair SY. Effectiveness of motivational interviewing on lifestyle modification and health outcomes of clients at risk or diagnosed with cardiovascular diseases: a systematic review. Int J Nurs Stud. 2016:53:331-41.

26. Anastopoulou K, Fradelos EC, Misouridou E, Kourakos M, Berk A, Papathanasiou IV, Kleisiaris C, Zyga S. Moderating nutritious habits in psychiatric patients using Transtheoretical model of change and counseling. Adv Exp Med Biol. 2017:988:63-71.

27. Sun Zhengqiu XY. Medical statistics, vol. 835. 4th ed: People's Medical Publishing House; 2014. http://books.ipmph.com/books/detail/7652.shtml.

28. Bingxiang Y. Effects of motivational interviewing and stage-matched intervention on depression of COPD inpatients: Central South University; 2009. https://kns.cnki.net/kns/brief/default_result.aspx.

29. Mingyuan Z. Handbook of psychiatric evaluation scale. Changsha: Hunan Science And Technology Publishing House; 1998.

30. Yuzhong W. Publication of psychological assessment scale manual (19992010) publish. J Xinxiang Med Coll. 2012;29(10):804

31. Levesque DA, Van Marter DF, Schneider RJ, Bauer MR, Goldberg DN, Prochaska JO, Prochaska JM. Randomized trial of a computer-tailored intervention for patients with depression. Am J Health Promot. 2011;26(2): 77-89.

32. Evers KE, Prochaska JO, Johnson JL, Mauriello LM, Padula JA, Prochaska JM. A randomized clinical trial of a population- and transtheoretical modelbased stress-management intervention. Health Psychol. 2006;25(4):521-9.

33. Sonia Lippke RS, Ziegelmann JP, Scholz U, Schüz B. Testing stage-specific effects of a stage-matched intervention: a randomized controlled trial targeting physical exercise and its predictors. Health Educ Behav. 2010;37(4): 533-46.

34. Skaal $\mathrm{L}$, Pengpid $\mathrm{S}$. The predictive validity and effects of using the transtheoretical model to increase the physical activity of healthcare workers in a public hospital in South Africa. Transl Behav Med. 2012;2(4): 384-91.

35. SCH L-XZ, Sit JWH, He H-G. Retraction: Effects of a transtheoretical modelbased exercise stage-matched intervention on exercise behaviour and quality of life in patients with coronary heart disease: a randomized controlled trial. J Adv Nurs. 2014;70(10):2414.

36. Prochaska JO, Redding CA, Evers KE. The transtheoretical model and stages of change. Health Behav Health Educ. 2008;22(22):97-121.
37. Hoy J, Natarajan A, Petra MM. Motivational interviewing and the Transtheoretical model of change: under-explored resources for suicide intervention. Community Ment Health J. 2016;52(5):559-67.

38. Yun-Mi Lee N-HP. Young-Hee Kim: self-efficacy and depression across the stages of change for exercise among middle aged women in Korea. J Korean Acad Nurs. 2006;36(4):587-95.

39. Prochaska JO, Velicer WF, Rossi JS, Goldstein MG, Marcus BH, Rakowski W, Fiore C, Harlow LL, Redding CA, Rosenbloom D, Rossi SR. Stages of change and decisional balance for 12 problem behaviors. Health Psychol. 1994;13(1): 39-46.

40. Fallon EAHH, Nigg CR. The transtheoretical model and exercise adherence: examining construct associations in later stages of change. Psychol Sport Exerc. 2005;6(6):629-41.

41. Bo Y. The Transtheoretical model of health behavior change. Chin Ment Health J. 2007:21(03):194-19.

42. Petrocelli JV. Processes and stages of change: counseling with the Transtheoretical model of change. J Couns Dev. 2011;80(1):22-30.

43. Bandura A. Self-efficacy mechanism in human agency. Am Psychol. 1982; 37(2):122-47.

44. Lim SH, Chan SW, He HG. Patients' experiences of performing self-care of stomas in the initial postoperative period. Cancer Nurs. 2015;38(3):185-93.

45. Judge TA, Jackson CL, Shaw JC, Scott BA, Rich BL. Self-efficacy and workrelated performance: the integral role of individual differences. J Appl Psychol. 2007;92(1):107-27.

\section{Publisher's Note}

Springer Nature remains neutral with regard to jurisdictional claims in published maps and institutional affiliations.

\section{Ready to submit your research? Choose BMC and benefit from:}

- fast, convenient online submission

- thorough peer review by experienced researchers in your field

- rapid publication on acceptance

- support for research data, including large and complex data types

- gold Open Access which fosters wider collaboration and increased citations

- maximum visibility for your research: over $100 \mathrm{M}$ website views per year

At BMC, research is always in progress.

Learn more biomedcentral.com/submissions 